\title{
Promoting social entrepreneurship product
}

\author{
Marga Zhivitere, Viktoriia Riaschenko \\ Ventspils University College researcher Centre for Entrepreneurship Innovation and Regional Development \\ 101 I Inženieru Street , LV-3601, Ventspils, Latvia \\ ISMA university, Faculty of Department of Management. Address: 1 Lomonosova Str., build. 7, Riga, LV-1019,
} Latvia.

\begin{abstract}
The object of the research are the social entrepreneurs and its business development. The aim of the research is to discuss existing marketing strategies applied to social entrepreneurship and to offer possible ways of their improvement. The research is relevant and consistent with the increasing role of social entrepreneurship taking the full power throe the fast changing political, economic, socio cultural and technological circumstances of the $21^{\text {st }}$ century. While marketing the social entrepreneurship, the focus on marketing strategies must be revised. The research methodology includes both traditional and modern elements of marketing, such as marketing mix, strategies, customer segmentation and targeting, pricing altogether with the main elements of social entrepreneurship, such as social and economic aspects.

The results present thet in standard marketing strategies, the strategy for social entrepreneurs should include segmentation of the customers and consumers by taking into consideration standard criteria (such as geographical, demographical, psychographic and behavior segmentation) but also implementing own criteria most adequate for the products they are currently interested to produce. It is important which factors are significant enough to take decisions of expansion, harvest or liquidation of products.
\end{abstract}

Keywords: marketing mix, marketing strategy, social entrepreneurship, social sustainability.

\section{INTRODUCTION}

Every type of business consists of following market participants: suppliers, intermediaries, companies, competitors and customers. Social entrepreneurship, as an object of the research, is also a part of the modern business environment with the one exception - customers of the product or service produced by such companies are not often the consumers or targeted customers of the related goods. In many cases the decision maker is that paying part, such as the government, a foundation, an individual sponsor or a funder. The ultimate consumer in many cases gets an access to services at no cost or at discounted prices through the payer. This additional customer profile makes an issue of this research as in the case of social entrepreneurship the focus on marketing strategy should be slightly different from traditional businesses.

The aim of the research is to discuss existing marketing strategies applied to social entrepreneurship and to offer possible ways of their improvement. The research is relevant and consistent with the increasing role of social entrepreneurship taking the full power throe the fast changing political, economic, socio cultural and technological circumstances of the $21^{\text {st }}$ century.

While marketing the social entrepreneurship, the focus on marketing strategies must be revised. For social entrepreneurs sometimes main benefit is not a profit but grow of positive reputation. This can be achieved throe dissemination of marketing strategies, devoted to enhance the image through public recognition. The same can be stated both for customers of socially related goods and for the final consumers. The goods they buy may mean to them not only profitable deal and cost optimization but also can increase their intangible sense of social outcome.

\section{MATERIALS AND METHODS}

The research methodology includes both traditional and modern elements of marketing, such as marketing mix, strategies, customer segmentation and targeting, pricing altogether with the main elements of social entrepreneurship, such as social and economic aspects. Works of various authors related to the research field were analyzed, such as Ph. Kotler (Principles of Marketing) [8], J. Dees (Entreprising nonprofits...) [3], J. Boschee (Strategic Marketing...) [2] and others[5,7,9]. Tools of the research include observation, experiment, analysis of the specific literature and statistical methods, interviews with participants of social entrepreneurship. Ethics of the research must take into consideration specific groups of the targeted consumers that often represent different minorities, people with disabilities, low income population and taking into attention rapidly changing political situation in European Union - refugee groups.

While discussing a role of marketing in the social entrepreneurship an additional element should http://dx.doi.org/10.17770/etr2017vol1.2647 
be stated among the main elements of marketing mix - and this is a social impact. The social mission, its goals and objectives should be analyzed altogether with product, its price, distribution place and necessary promotion. When evaluating special target group for social business following questions should be stated and discussed by decision makers:

1. Most segments of the final consumers should be stated.

2. Which of them are reached and served in a most effective way with the most limited resources?

3. How is it possible to attract more of prospective consumer segments? Which customers should be involved then?

4. Is the cost consistent with the social outcome?

5. Are there certain ways to decrease the cost without reducing the impact provided?

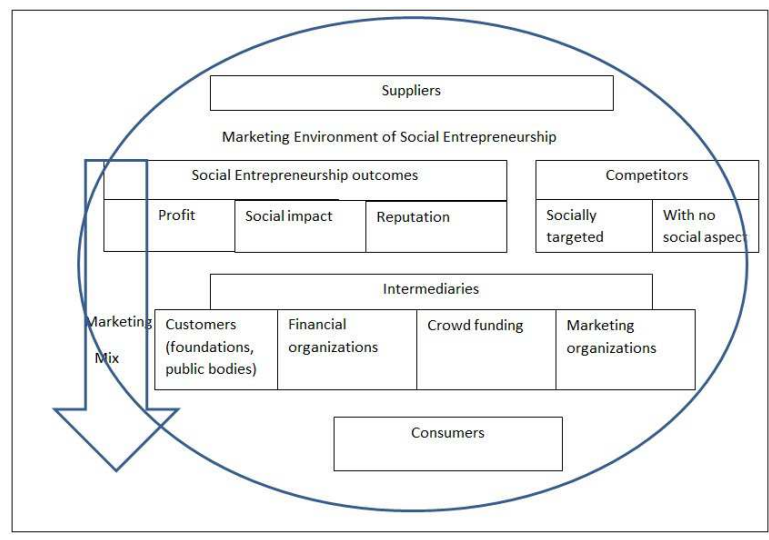

Fig.1 Marketing environment of social entrepreneurship

On a figure 1 there is marketing environment of social entrepreneurship analyzed. Unlike the tradition entrepreneurs, social entrepreneurs should take care not only about their profit maximization. Social impact and increase of positive brand or company`s image reputation must also be taken into attention. As a company, it meets on a market with competitors who could have better market proposition or have/ have not been socially targeted. In this case there also should be different strategies applied. Sometimes socially targeted competitors have the same intention with the company and their interests intersect or match. In this case competitor may become a partner or even intermediary on a way to a related targeted auditorium. For example a company that produces food with the purpose to disseminate for a special social group (as homeless people) and sponsored by a public body or a foundation may join with food disseminators on wheels that serve the same or similar groups of people. In this case resources spent on promotion and distribution elements of marketing mix will be decreased and total cost of the product will become lower as well.

However the situation when socially related entrepreneur meets with a competitor who doesn't have a social relation is quite opposite from the previously stated. In this case the development of a situation often goes with more pessimistic prognosis for market growth possibilities for a social entrepreneur. As an example there can be mentioned price comparison experiment that was hold between rugs sellers in Latvia. "Lude" [1] is a company very closely related to the social entrepreneurship as it uses recycled textile materials to produce rugs. Although the design is developed by professional designers, these rugs are made by the group of senior people. The intention of the business is not only to sell textile rugs and get profit but also to increase social impact by improving both financial and social status of the elderly people. The production of "Lude" could be easily found in Latvia, mostly in shops related to the Latvian crafts and design and also at online stores, such as etsy.com [4]. The price on a textile rug sized $70 \times 120 \mathrm{~cm}$ can vary but starts with 90 EUR. Comparing the price with similar on quality (recycled textile) and size $(70 \times 140 \mathrm{~cm}) \mathrm{rug}$, offered for a sale by a competitor with no social relation, such as "Jyusk", there is a price starting from 19.99 EUR.

Formally it looks as there is no much sense in purchasing "Lude" rugs as its price is 4.5 times higher than offered by the competitor. However there is an importance of the third aspect - reputation of the social entrepreneurship seen very clearly. When people purchase "Lude" rugs they understand perfectly the reason they are ready to overpay for. The sense of social responsibility they get. This is an additional aspect to marketing mix, intangible outcome that should be emphasized and underlined by marketing tools.

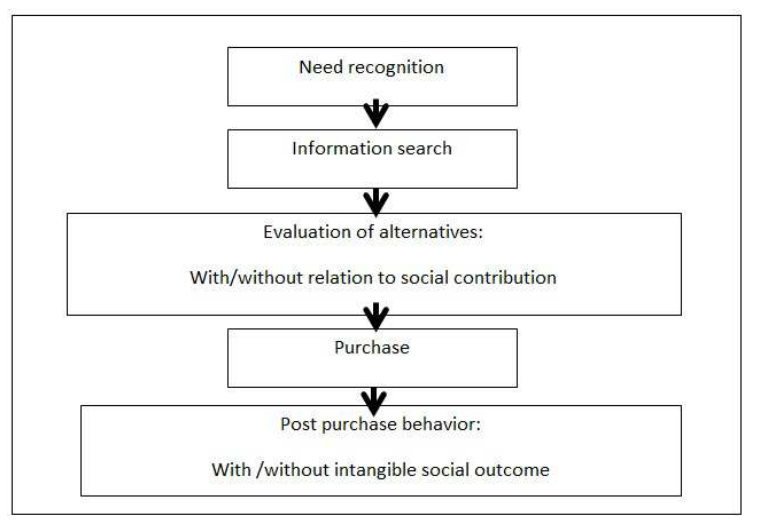

Fig. 2 Buyer behavior process in case of socially related goods purchase

Intangible outcome customers and consumers get when purchasing goods or services from social entrepreneurs. This outcome should be positioned as an additional element of customer's response to the marketing mix. Social impact from marketing mix meets intangible outcome, the sense that customers get while buying socially related products. In this 
case the buyer behavior process could be described as stated on a figure 2 .

\section{RESULTS AND DISCUSSION}

As being mentors of social entrepreneurs for past 2 years in the frames of the NEW D(o)or initiative, the authors were participating in various meetings, interviews and lectures with the project participants - social entrepreneurs from Latvia, Ukraine, Lithuania and Russian Federation [10]. During these meetings several important factors were obtained:

1. Negative attitude to marketing from the side of social entrepreneurs. Mostly related to weak knowledge of the subject and interpreting marketing as a tool of profit maximization for companies with ignorance of needs of a society at large.

2. Main marketing strategies were learned firstly during the meetings with mentors and invited lecturers. Before that the achievements of social entrepreneurs - project participants were made mostly thanks to their inborn sense of market behavior.

3. Fear of rejection. This is equal to the described by Ira Kalb, the marketer who also delivered a course of marketing lectures to the social entrepreneurs in USA: "Those that tend to be more intelligent and socially-conscious (the ones who gravitate to social entrepreneurship) tend to be more sensitive to rejection - a natural part of the sales process. The fear of rejection is often given as a reason why so many shun marketing/sales" [7].

During the meetings with the social entrepreneurs it should be explained that this stated perception of marketing they have is wrong. According to the definition of marketing given by the marketing guru, Ph. Kotler: "Satisfying needs and wants through an exchange process" [8]. It is clear money and profit maximization are not mentioned among the main objects and goals in the theories of modern marketing. Quite opposite - the concept of marketing was born as a need of a new response while old market concepts - the production, the product and the selling concept showed their imperfection in attempts to get new customers and to achieve the market share growth. Then was offered modern marketing approach - first sense the needs of current and potential customers and then give an adequate response with the product that will satisfy their needs. Needs satisfaction - this approach is more than consistent with the orientation of social entrepreneurship which aim is to increase social impact exactly buy satisfying those targeted segments that due to different reasons remained unsatisfied by traditional businesses before.

While marketing their social offers, social entrepreneurs may often meet following problems:

1. Incentives of third party payers (intermediaries or customers) do not align with the social mission or the interests of the consumers. For example, a public health organization may be pressured to lower payments for drug rehabilitation services to a point lower than practical. In this case, organizations compete to be the lowest cost provider, which may compromise social impact.

2. Paying customers cannot accurately assess quality of programs or services. Measuring social value is difficult. As a result, customers lack adequate information to gauge the quality of social goods and services. Social value is not determined by customer demand or a lack thereof.

3. Social benefits created by social ventures often exceed consumer value. The total societal benefits surpass what they directly provide to the individuals they serve. This would be seen in programs that prevent youth from committing crimes that generally have a high cost to society or reducing the incidence of spreading diseases among the healthy population. Alternatively, high consumer demand does not necessarily indicate high social value. Homeless shelters serving alcoholic beverages may demonstrate high demand, but this demand is not a sign that these shelters would be superior. [3]

Going back to marketing strategies that should be offered to social entrepreneurs there can be mentioned special strategic matrix, developed especially for the social entrepreneurs by the scientist Jerr Boschee [2]. It is stated that making strategic marketing decisions, however, is more difficult for a social entrepreneur than it is for either a traditional nonprofit or a commercial business, both of which are primarily concerned with a single bottom line. A traditional nonprofit will continue offering products and services that have a significant social impact even if they lose money; commercial enterprises will not. Social entrepreneurs, on the other hand, are equally concerned both with social impact and income, and that means they must simultaneously analyze the social impact and financial viability of each product and service - and only then they are ready make decisions about which ones to expand, nurture, harvest or kill.

Table 1

The Strategic Marketing Matrix for Social Entrepreneurs [2]

$\begin{array}{lll} & \begin{array}{l}\text { Positive financial } \\ \text { returns }\end{array} & \begin{array}{l}\text { Negative financial } \\ \text { returns }\end{array} \\ \begin{array}{l}\text { Significant social } \\ \text { impact }\end{array} & \text { Expand } & \text { Nurture } \\ \text { Minimal social impact } & \text { Harvest } & \text { Kill }\end{array}$

The matrix, given at the table 1 is simple and easy way for social decision makers to think about the intersection of social impact and financial returns. It can be expanded to measure the consistence of the degree of social need being addressed and the anticipated financial results. Next matrix could be used when more detailed analysis is needed. It measures the relationship between the degree of 
social need being addressed and the anticipated financial results:

Table 2

The Expansion of the Strategic Marketing Matrix for Social Entrepreneurs, adapted from [2]

$\begin{array}{llll}\begin{array}{l}\text { Potential Significant } \\ \text { level of } \\ \text { reachable } \\ \text { profit/losses }\end{array} & \text { Modest } & \begin{array}{l}\text { Modest } \\ \text { losses }\end{array} & \begin{array}{l}\text { Significant } \\ \text { losses }\end{array} \\ \begin{array}{l}\text { Volume of } \\ \text { social need }\end{array} & & & \\ & & & \\ \text { Critical Expand } & \text { Expand } & \text { Nurture } & \text { Kill } \\ \text { Sizeable Expand } & \text { Expand } & \text { Nurture } & \text { Kill } \\ \text { Minimal Harvest } & \text { Harvest } & \text { Kill } & \text { Kill } \\ \text { No social Kill } & \text { Kill } & \text { Kill } & \text { Kill } \\ \text { need } & & & \end{array}$

To use this expanded matrix analysis a social entrepreneur first has to make following steps:

1. To divide a market into all possible segments and to answer a question of each of the selected segments.

2. How many people of the segment are ready or are able to pay for this product and how strong is their need?

3. Are there any intermediaries or customers, as public bodies, available to cover these expenses to that related segment?

4. How all elements of marketing mix can be used or updated to make differentiation and positioning of the product to the related segment?

5. Environmental forces - how significant their role is? Are these factors playing positive or negative role? Are they helpful or damaging? How is possible to use the opportunities and decrease the role of the threats?

6. Who are you main competitors? Are they also representatives of the social entrepreneurship or do they represent traditional field of a business? How is possible to evaluate the threats from them?

7. In money equivalent - how is it possible to measure the market?

8. Are there any other opportunities for your product's grow within this segment?

9. What is a current position of you product in this market? It there market grow, is it constant or declining? Which trends is possible to predict right now?

10. What is the fixed and variable cost? What is the perspective for profit or losses? A preliminary calculation should be provided.

The same as in standard marketing strategies, the strategy for social entrepreneurs should include segmentation of the customers and consumers by taking into consideration standard criteria (such as geographical, demographical, psychographic and behavior segmentation) but also implementing own criteria most adequate for the products they are currently interested to produce providing also a social impact. For example, a company that produce necessary equipment for the sportsmen of Paralympic games can disseminate a table of different levels of these sportsmen disabilities. According to the level of disability each of them needs own equipment.

Next, following strategies should be applied to each group of products dedicated to each special segment:

1. Products with social impact able to bring potentially large profit should be expanded and require most of the resources.

2. Programs with a large social impact but not yet achieved financial stability should de additionally nurtured.

3. If the company plans to continue to support its socially sustainable products with good financial profit but with low social impact - this should be revised or harvested.

4. Products, both low with their social impact and profit should be taken away from a market or "killed".

Last but not least step that should be taken into attention when developing a marketing strategy for a social entrepreneurship should be how to measure which factors are significant enough to take decisions of expansion, harvest or liquidation of products. Following factors then should be taken into attention:

1. Significant success factors. Obviously the business must be profitable, the team should be strong and trustful, price should differ in a better side from competitors. There is also possible to mention delivery speed, sales volume, purchase convenience, reputation, amount of intermediaries, power of suppliers and much more.

2. Environment forces, both internal, micro and macro should be properly analyzed. Some of them, such as internal and micro is possible to control, some are so large that it is only possible to be informed about their existence. However in any case the entrepreneur should be forewarned.

3. Competitors and their power. As was shown already, some of the competitors may rely to the same field of the social entrepreneurs. Some of them can play on the same field but with no belonging to the social entrepreneurship. It was proved in case with textile rugs experiment that those entrepreneurs not related to social impact sometimes can offer better price offer to a customer as they don't have to include expenses on social aspects in their self-cost of a product. Despite the fact the total contribution to a society at large provided by social entrepreneurs is more significant, customers still can choice a product with no social component in a short run perspective.

Altogether all these three factors could be analyzed together in a matrix. Significant factors, that might bring a success and environmental forces with lower or higher level of impact to a product and to the development of social entrepreneurial business at large should be measured by an entrepreneur or even by his team or by invited experts, such as mentors, 
business angels etc. Each of the factors should have its own weight; the total should be equal to 100 per cent. Then each of competitor`s products altogether with the product of a social entrepreneur must be ranked. Total ranking should be considered depending on a amount of the research participants, for example, if there are five participants (the social entrepreneur and his four competitors), the total ranking must be five. Each of the participants will get multiplied result of ranking and the weight percentage.

\section{IV.RESULTS}

As an example there is given analysis of already well known social entrepreneurial company "LUDE" which main area of business is handmade manufacture by senior women of textile rugs, made from recycled or second hand materials. These products are compared to the other offered at the same market field such as etsy.com [Etsy.com, 2015], an online network for buy and sell of home made crafts.

Table 3

Competitive Analysis for Social Entrepreneurs on Example of Textile Rugs

\begin{tabular}{l|l|lllllll}
\hline & & \multicolumn{3}{c}{$\begin{array}{l}\text { The Charkha, ADRugs, } \\
\text { India }\end{array}$} & \multicolumn{3}{c}{ Lutvia, } \\
& & Latvia \\
\hline Factors & Weight & Rank & Score & Rank & Score & Rank & Score \\
\hline S.S.F.1 & $20,00 \%$ & 2 & 0,4 & 3 & 0,6 & 1 & 0,2 \\
S.S.F. 2 & $20,00 \%$ & 2 & 0,4 & 1 & 0,2 & 3 & 0,6 \\
S.S.F. 3 & $15,00 \%$ & 1 & 0,15 & 3 & 0,45 & 2 & 0,3 \\
S.S.F. 4 & $20,00 \%$ & 1 & 0,2 & 3 & 0,6 & 2 & 0,4 \\
E.F.1 & $20,00 \%$ & 3 & 0,6 & 2 & 0,4 & 1 & 0,2 \\
E.F.2 & $5,00 \%$ & 2 & 0,1 & 1 & 0,05 & 3 & 0,15 \\
Total & $100 \%$ & & 1,85 & & 2,3 & & 1,85
\end{tabular}

Significant success factor 1: social impact

Competitor 1, The Charkha, India. These rugs are made from recycled materials (former Indian sari dress), so there is a social impact. This is stated in the description of the product, so customers understand the social outcome they gain at a purchase.

Competitor 2. ADRugs. These rugs are made from recycled materials (as described on a website), so there is a social impact.

Lude - these rugs are made from recycled materials or second hand dress by elderly people, so there is double social impact. This is stated in the description of the product, so customers understand the social outcome they gain at a purchase [1].

Significant success factor 2: price

Competitor 1, The Charkha. Prices for rugs can vary depending on a size, but starts from 63.89 EUR

Competitor 2, ADRugs. Price can vary, but starts from 32.85 EUR.

Lude: Prices for rugs can vary depending on a size, but starts from 80 EUR. (which is cheaper comparing to the prices listed on their own site, from 90 EUR). It is clear, that in a question of price Lude has the weakest position and this should be seriously revised.

Significant success factor 3: price assortment

Competitor 1, The Charkha. There are 53 different items available for sale.

Competitor 2, ADRugs. There are only 5 items on site.

Lude: 37 items are available for sale at etsy.com

Other significant success factors that might be taken into consideration:

Significant success factor 4: promotion and positive reputation

Feedbacks and positive reviews (for example, The Charkha has 56 reviews and got favorite mark by 101 people, Lude has only 1 review and got favorite mark by 7 persons, however ADRugs has no reviews and only 2 favorites).

Environmental forces should be also taken into attention. E.F.1: for example, both ADRugs and Lude are located in Latvia, so it is easier to deliver within one country. Environmental forces, such as political implications, delay with delivery etc. may destroy logistics process for The Charkha, located in India). Lude gets better ranking due to more positive feedbacks from customers who already had received the rugs.

E.F.2 : demographical situation. Lude gets better ranking because it gives paid work and offer additional social activities to the group of population which is constantly growing in Latvia - the senior people. This group is traditionally suffering from low income and current prognosis on demographical situation of the country predict that this part of population will continue growing. ADRugs gets the lowest ranking as there is no mention about their team structure and The Charkha is giving work to poor women of India who traditionally suffer from unemployment and negative attitude from other parts of the society.

Let's look at the business model as an example of social entrepreneurship company "Lude" [Lude, 2015] a. In this case, the business model is the business concept underlying the practice [5]. It includes four basic components: costumer interface (1) a core strategy, (2) strategic resources (3), the value net (4) (network of social support on the basis of common values).

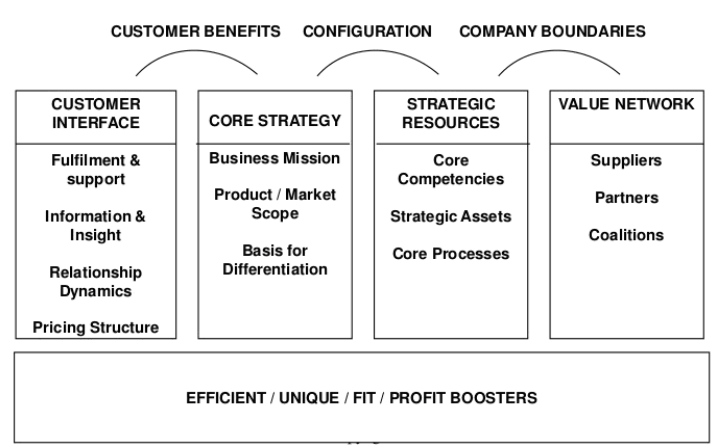

Fig. 3 Component of business model 
Table 3.

Overview of the components of business models of social entrepreneurship

Costumer interface The production of "Lude" could Customer interface has be easily found in Latvia. The four elements: fulfillment and price of the products is high. support, information and insight, Buyers pay for social relationship dynamics, and pricing responsibility. structure.

Core strategy includes Company "Lude" uses recycled business mission, product/market textile materials to produce rugs scope, and basis for

differentiation. Controlled items or

zone preemptive influence within the value network

\section{Strategic resources}

include core competencies,

strategic assets, and core

processes. Requirements for

strategic resources included in the

business model

Value net. Integration of target

groups
- Investment

- Risk Management

- A large proportion of workers is also an owner

- Strong business relations

(suppliers - customers) within group
- Human resources

The authors of this paper agree with the conclusions Schoen and Mair [9]:

1) To fulfill its mission, and timely resolution of problems of the successful organization of social entrepreneurship is to create a social network's value at an early stage of its development.

2) The successful organization of social entrepreneurship carefully take into account their resource needs and in line with the strategy of developing the resource, which should be integrated into the business model at a very early stage of development of the organization.

3) The successful organization of social entrepreneurship integrates its target group in the social network's value at an early stage of development of the organization.

These aspects need to be considered during the formation of a marketing strategy for social enterprise.

To summarize it is possible to say despite the fact The Charkha and Lude have market offerings filled with social impact, still the company with the lowest share of social sustainability offers the cheapest price and fast delivery. However if positive feedbacks of customers are very important especially for those concerned about social outcome to get. So, it is obvious that Lude is on a right way of development, however they have to revise their price policy.

\section{CONCLUSION}

While marketing the social entrepreneurship, the focus on marketing strategies must be revised. For social entrepreneurs sometimes main benefit is not a profit but grow of positive reputation. This can be achieved throe dissemination of marketing strategies.
In the social entrepreneurship an additional element should be stated among the main elements of marketing mix - and this is a social impact. Intangible outcome customers and consumers get when purchasing goods or services from social entrepreneurs. This outcome should be positioned as an additional element of customer's response to the marketing mix. Social impact from marketing mix meets intangible outcome, the sense that customers get while buying socially related products.

It is stated that making strategic marketing decisions, however, is more difficult for a social entrepreneur than it is for either a traditional nonprofit or a commercial business, both of which are primarily concerned with a single bottom line. A traditional nonprofit will continue offering products and services that have a significant social impact even if they lose money; commercial enterprises will not. Social entrepreneurs, on the other hand, are equally concerned both with social impact and income, and that means they must simultaneously analyze the social impact and financial viability of each product and service - and only then they are ready make decisions about which ones to expand, nurture, harvest or kill.

The same as in standard marketing strategies, the strategy for social entrepreneurs should include segmentation of the customers and consumers by taking into consideration standard criteria (such as geographical, demographical, psychographic and behavior segmentation) but also implementing own criteria most adequate for the products they are currently interested to produce providing also a social impact.

To measure which factors are significant enough to take decisions of expansion, harvest or liquidation of products, following then should be taken into attention: significant success factors; environment forces; competitors and their power.

\section{ACKNOWLEDGMENTS}

This study was partly supported by the New D(o)or, starptautiska sociālo inovāciju platforma. Link: http://www.newdoor.lv

[1] About Lude. Textile rugs. Link: http://www.lude.lv/?section=about (accessed 17.01.2017)

[2] Boschee J. Strategic Marketing for Social Entrepreneurs. Social Enterprise Reporter, 20015.

[3] Dees, J.G., Emerson, J., \& Economy, P. Enterprising Nonprofits: A Toolkit for Social Entrepreneurs. Toronto: John Wiley \& Sons, 2001

[4] Etsy.com https://www.etsy.com/ru/search/handmade?q=textile+rug\&sh ip_to=LV (accessed 17.01.2017)

[5] Hamel, G. Leading the revolution. Harvard Business School Press, Boston, 2000

[6] Jysk product sortment. Link: http://www.jysk.lv/paklajsacre.html (accessed 17.01.2017)

[7] Kalb Ira. Marketing: the missing ingredient in social entrepreneurship. Huff Post Business newspaper, 04.01.2015. 
Marga Zhivitere, et al., / Environment. Technology. Resources, (2017), Volume I, 309-315

[8] Kotler Philip, Armstrong Gary. Principles of Marketing. 14 $4^{\text {th }}$ Edition. Pearson Prentice Hall, 2007.

[9] Mair, J., Schoen, O. Social Entrepreneurial Business Models: An Exploratory Study. ESE Business School, University of Navarra, WP №610 October 2005.

[10] New D(o)or, social initiative. Link: http://www.newdoor.lv (accessed on 17.01.2017) 